\title{
Determinan Keluhan Muskuloskeletal pada Tenaga Kerja Wanita
}

\section{Determinant of Musculosceletal Disorders Complaint on Female Workers}

\author{
Iwan Muhamad Ramdan, Tiyanpri Bayu Laksmono
}

\author{
Bagian Kesehatan dan Keselamatan Kerja Fakultas Kesehatan Masyarakat Universitas Mulawarman
}

\begin{abstract}
Abstrak
Gangguan muskuloskeletal merupakan masalah kesehatan dan keselamatan kerja yang penting karena masih berkontribusi pada penurunan produktivitas kerja. Penelitian ini bertujuan untuk mengetahui hubungan umur tenaga kerja, masa kerja, indeks massa tubuh, dan sikap kerja dengan keluhan gangguan muskuloskeletal pada tenaga kerja wanita di unit produksi bagian kupas di PT SSM Kalimantan Timur. Penelitian kuantitatif yang menggunakan desain penelitian cross sectional ini dilakukan pada tenaga kerja wanita bagian pengupasan yang berjumlah 46 orang (total sampling). Variabel bebas penelitian terdiri dari umur, masa kerja, indeks massa tubuh, dan posisi kerja, sementara variabel terikat adalah keluhan gangguan muskuloskeletal. Analisis data yang digunakan adalah uji chi-square dengan level signifikansi 0,05 (5\%). Hasil penelitian menunjukkan tidak terdapat hubungan umur dengan keluhan gangguan muskuloskeletal $(p=0,066)$, terdapat hubungan yang signifikan antara masa kerja $(p=0,044)$, indeks massa tubuh $(p=0,025)$, dan sikap kerja $(p=0,001)$ dengan keluhan gangguan muskuloskeletal. Perusahaan disarankan untuk membuat kursi kerja yang ergonomis, melakukan rotasi kerja, dan melakukan pelatihan dengan materi tata cara kerja yang ergonomis.
\end{abstract}

Kata kunci: Gangguan muskuloskeletal, produktivitas, sikap kerja

\footnotetext{
Abstract

Musculoskeletal disorders are still a health and safety issue that needs to be examined in more depth, because it still contributes to the decline in labor productivity. The objective of this research was to know the relationship between age, working periode, body mass index and work posture with complaint of musculoskeletal disorders. Quantitative research with cross sectional approach has been done on 46 (total sampling) female labor in peeling sections. The independent variables consisted of age, year, body mass index, and work posture, while the dependent variable was the complaint of musculoskeletal disorders. The data analysis used was chi-square test with a significance level of $0.05(5 \%)$. The results showed no associa-
}

tion between age with symptoms of musculoskeletal disorders $(p=0,066)$, there is a significant association between working period ( $p=0,044)$, body mass index $(p=0,025)$, and work posture $(p=0,001)$ with complaints of musculoskeletal disorders. Companies are advised to make an ergonomic office chair, job rotation, and training with ergonomic material working procedures.

Keywords: Musculoskeletal disorders, productivity, work posture

\section{Pendahuluan}

Salah satu pilar keberhasilan Keselamatan dan Kesehatan Kerja (K3) adalah penerapan ergonomi di tempat kerja. Ergonomi merupakan suatu komponen kegiatan $\mathrm{K} 3$ yang menyerasikan pekerjaan tenaga kerja secara optimal untuk pencapaian efisiensi, efektivitas, dan kenyamanan bekerja dalam rangka peningkatan produktivitas kerja. Akan tetapi, permasalahan ergonomi di dunia industri dirasakan masih belum optimal. Hal ini disebabkan banyak industri yang menggunakan mesin dalam proses kerja tetap membutuhkan tenaga manusia yang mempunyai keterbatasan fisik dalam menangani proses manual. Keterbatasan inilah yang menimbulkan faktor risiko terjadinya berbagai penyakit akibat kerja.

Salah satu penyakit akibat kerja yang sering muncul dari ketidakserasian tenaga kerja dengan pekerjaan adalah gangguan muskuloskeletal. Keluhan muskuloskeletal adalah keluhan pada bagian otot skeletal yang dirasakan oleh seseorang mulai dari keluhan sangat ringan sampai berat. Apabila otot menerima beban statis

Alamat Korespondensi: Iwan Muhamad Ramdan, Departemen K3 FKM Universitas Mulawarman, Gd. Perpustakaan Lt. 3 Jl. Kuaro Kampus Gn. Kelua,Samarinda, Hp.08125424118,e-mail: i_oneramdan@yahoo.co.id 
secara berulang dan dalam waktu yang lama dapat menyebabkan keluhan berupa kerusakan pada sendi, ligamen, dan tendon. Keluhan hingga kerusakan ini biasanya diistilahkan dengan keluhan musculoskeletal disorders atau cedera pada sistem muskuloskeletal. Secara garis besar, keluhan otot dapat dikelompokkan menjadi dua, yaitu keluhan sementara (reversible) dan keluhan menetap (persistent). ${ }^{1}$

Gangguan muskuloskeletal masih merupakan masalah dalam produktivitas kerja, seperti yang terjadi di Jerman, gangguan muskuloskeletal telah menyumbang sebanyak $20 \%$ ketidakhadiran dan sebanyak $50 \%$ pensiun dini. ${ }^{2}$ Sementara di United Kingdom, sekitar 43,4\% angka kesakitan dan cedera berkaitan dengan gangguan muskuloskeletal. Cedera tersebut banyak terjadi $45 \%$ pada punggung, $22 \%$ pada tangan, dan $13 \%$ pada lengan. ${ }^{3}$ Data lainnya menyebutkan di Amerika terjadi sekitar 6 juta kasus per tahun atau rata-rata 300 - 400 kasus per 100.000 pekerja. Keluhan muskuloskeletal telah menyumbang $29 \%$ dari total angka penyebab kecelakaan kerja dan penyakit akibat kerja. Kejadian ini meningkat $6 \%$ dari tahun sebelumnya menjadi 155 kasus per 100.000 pekerja. Masalah ini mengakibatkan pekerja harus istirahat di rumah (lost day) selama rata-rata 20 hari, dengan variasi mulai dari ringan hingga cacat permanen. Biaya yang harus dikeluarkan akibat Material Safety Data sheet ini mencapai rata-rata $\$ 14.726$ (lebih dari 130 juta rupiah). ${ }^{4}$ Di Indonesia, berdasarkan dari hasil studi Departemen Kesehatan tahun 2005, terdapat sekitar $40,5 \%$ penyakit yang diderita tenaga kerja sehubungan dengan pekerjaan. Gangguan kesehatan yang dialami pekerja, menurut penelitian yang dilakukan terhadap 482 pekerja di 12 kabupaten/kota di Indonesia, $16 \%$ di antaranya berupa gangguan muskuloskeletal. Penelitian Pusat Studi Kesehatan dan Ergonomi ITB tahun 2006 - 2007 memperoleh data sekitar $40-80 \%$ pekerja melaporkan keluhan muskuloskeletal. ${ }^{5}$

Berbagai faktor yang dapat menyebabkan gangguan sistem muskuloskeletal dibedakan atas penyebab primer, sekunder, dan kombinasi. Penyebab primer antara lain meliputi peregangan otot yang berlebihan, aktivitas berulang, dan sikap kerja tidak alamiah. Penyebab sekunder antara lain meliputi tekanan, getaran, dan paparan suhu dingin yang berlebihan atau mikroklimat. Penyebab kombinasi antara lain umur, jenis kelamin, kebiasaan merokok, aktivitas fisik, kekuatan fisik, dan ukuran tubuh. ${ }^{6}$

PT SSM yang merupakan salah satu perusahaan cold storage di Kalimantan Timur bergerak di bidang ekspor udang beku dan olahan udang. Perusahaan tersebut mempunyai sekitar 381 tenaga kerja, sebagian besar perempuan dengan beberapa posisi kerja yang berbeda. Salah satu jenis pekerjaan yang belum dapat dilaksanakan secara mekanis adalah bagian pengupasan, se- hingga masih dilakukan secara manual oleh tenaga kerja. Pada bagian produksi, jumlah tenaga kerja lebih banyak dibandingkan bagian lain dan jenis pekerjaan dilakukan sambil berdiri selama jam kerja. Hal tersebut menjadi potensi terbesar yang dapat memicu keluhan gangguan muskuloskeletal bagi para pekerja di unit produksi tersebut. Penelitian ini bertujuan untuk mengetahui keluhan gangguan muskuloskeletal pada tenaga kerja di PT SSM serta faktor-faktor yang memengaruhinya.

\section{Metode}

Penelitian yang dilakukan adalah penelitian korelatif metode survei dengan menggunakan rancangan cross sectional. Variabel bebas terdiri dari umur, masa kerja, indeks massa tubuh, dan sikap kerja; sementara variabel terikat adalah keluhan gangguan muskuloskeletal. Penelitian dilakukan pada seluruh tenaga kerja bagian kupas di PT SSM berjumlah 46 orang (total sampling). Cara pengumpulan data yang digunakan terdiri dari metode kuesioner, metode observasi, dan pengukuran langsung. Instrumen penelitian yang digunakan adalah Nordic Body Map, Rapid Entire Body Assessment, dan lembar pengukuran indeks massa tubuh. Teknik analisis data yang digunakan dalam penelitian ini adalah metode chi square.

\section{Hasil}

Sebagian besar respoden $(52 \%)$ berada pada kisaran usia 28 - 36 tahun, sementara itu, pendidikan responden sebagian besar $47,8 \%$ berlatar pendidikan SD, sisanya $39,1 \%$ adalah SLTP, dan 13\% SLTA. Berdasarkan masa kerja, masa kerja baru sebanyak 31 orang $(67,4 \%)$, masa kerja sedang sebanyak 13 orang $(28,3 \%)$ dan masa kerja lama sebanyak 2 orang $(4,3 \%)$ dan berdasarkan indeks massa tubuh kategori kurus 2 orang $(4,3 \%)$, kategori normal sebanyak 30 orang $(65,2 \%)$, dan kategori gemuk sebanyak 14 orang $(30,4 \%)$. Berdasarkan tinggi badan yang dominan untuk proporsi terbesar adalah kelompok tinggi badan $151-153 \mathrm{~cm}$ sebanyak 11 orang $(24,0 \%)$ dan proporsi terkecil kelompok tinggi badan $160-162$ $\mathrm{cm} 1$ orang. Proporsi terbesar berat badan adalah kelompok $43-48 \mathrm{~kg}(28,3 \%)$ dan proporsi terkecil kelompok $61-66 \mathrm{~kg}$ dan $67-72 \mathrm{~kg}(4,4 \%)$. Sikap kerja dibagi menjadi 3 kategori, kategori rendah $(17,4 \%)$, sikap kerja kategori sedang $(69,6 \%)$ dan sikap kerja kategori tinggi $(13,0 \%)$. Keluhan gangguan muskuloskeletal dibagi dalam kategori rendah $(30,4 \%)$, kategori sedang $(69,6 \%)$, dan kategori tinggi $(13,0 \%)$. Selanjutnya, berdasarkan jenis keluhan gangguan muskuloskeletal, pada umumnya responden mempunyai banyak gangguan muskuloskeletal di setiap bagian tubuh. Hal ini terlihat dari jawaban "ya" dari setiap keluhan mempunyai persentase lebih besar dari jawaban "tidak". Proporsi keluhan terbanyak adalah di bagian jari tangan kiri dan kanan 
Tabel 1. Karakteristik Responden

\begin{tabular}{|c|c|c|c|}
\hline Karakteristik & Kategori & Frekuensi & $\%$ \\
\hline \multirow[t]{3}{*}{ Umur } & $19-27$ tahun & 18 & 36,8 \\
\hline & $28-36$ tahun & 24 & 52 \\
\hline & $37-42$ tahun & 5 & 10,9 \\
\hline \multirow[t]{3}{*}{ Pendidikan } & $\mathrm{SD}$ & 22 & 47,8 \\
\hline & SLTP & 18 & 39,1 \\
\hline & SLTA & 6 & 13 \\
\hline \multirow[t]{3}{*}{ Masa kerja } & Baru (<6 tahun) & 31 & 67,4 \\
\hline & Sedang (6-10 tahun) & 13 & 28,3 \\
\hline & Lama (>10tahun) & 2 & 4,3 \\
\hline \multirow[t]{3}{*}{ Indeks massa tubuh } & Kurus & 2 & 4,3 \\
\hline & Normal & 30 & 65,2 \\
\hline & Gemuk & 14 & 30,4 \\
\hline \multirow[t]{8}{*}{ Tinggi } & $139-141$ & 2 & 2,2 \\
\hline & $142-144$ & 4 & 8,7 \\
\hline & $145-150$ & 9 & 19,6 \\
\hline & $148-150$ & 9 & 19,6 \\
\hline & $151-153$ & 11 & 24 \\
\hline & $154-156$ & 5 & 10,8 \\
\hline & $157-159$ & 3 & 6,7 \\
\hline & $160-162$ & 1 & 2,2 \\
\hline \multirow[t]{7}{*}{ Berat badan } & $37-42$ & 6 & 13 \\
\hline & $43-48$ & 13 & 28,3 \\
\hline & $49-54$ & 12 & 25,9 \\
\hline & $55-60$ & 8 & 17,4 \\
\hline & $61-66$ & 2 & 4,4 \\
\hline & $67-72$ & 2 & 4,4 \\
\hline & $73-78$ & 3 & 6,6 \\
\hline \multirow[t]{3}{*}{ Sikap kerja } & Rendah & 6 & 13 \\
\hline & Sedang & 32 & 69,6 \\
\hline & Tinggi & 8 & 17,4 \\
\hline \multirow{3}{*}{$\begin{array}{l}\text { Keluhan } \\
\text { muskuloskeletal }\end{array}$} & Rendah & 14 & 30,4 \\
\hline & Sedang & 14 & 30,4 \\
\hline & Tinggi & 18 & 39,1 \\
\hline
\end{tabular}

Tabel 2. Hasil Analisis Determinan Keluhan Muskuloskeletal

\begin{tabular}{lccl}
\hline Variabel & Nilai p & Nilai Phi & Keterangan \\
\hline Umur & 0,066 & 0,872 & Tidak ada hubungan \\
Masa kerja & 0,044 & 0,461 & Ada hubungan \\
Indeks massa tubuh & 0,025 & 0,492 & Ada hubungan \\
Sikap kerja & 0,001 & 0,636 & Ada hubungan \\
\hline
\end{tabular}

(71,7\%), proporsi yang terkecil pada keluhan di bagian pantat $(19,6 \%)$ (Tabel 1).

Umur tenaga kerja tidak berhubungan dengan keluhan gangguan muskuloskeletal $(p=0,006)$; masa kerja berhubungan dengan keluhan gangguan muskuloskeletal $(\mathrm{p}=0,044)$; indeks massa tubuh tenaga kerja berhubungan dengan keluhan gangguan muskuloskeletal $(p=0,025)$, dan sikap kerja berhubungan dengan keluhan gangguan muskuloskeletal $(\mathrm{p}=0,001)$ (Tabel 2).

\section{Pembahasan}

Sebagian besar respoden ( $52 \%)$ berada pada kisaran usia 28 - 36 tahun, sebagian besar termasuk kategori usia muda dengan tingkat produktivitas yang tinggi. ${ }^{7}$ Sementara itu, pendidikan responden sebagian besar $47,8 \%$ berlatar pendidikan SD, sisanya $39,1 \%$ adalah
SLTP dan $13 \%$ SLTA. Tingkat pendidikan akan berpengaruh terhadap pengetahuan dan perilaku. ${ }^{8}$

Hasil analisis menyimpulkan bahwa umur tenaga kerja tidak berhubungan dengan keluhan gangguan muskuloskeletal. Hasil penelitian ini berbeda dengan penelitianpenelitian sebelumnya yang menyimpulkan umur tenaga kerja berhubungan dengan keluhan muskuloskeletal. Semakin bertambah usia tenaga kerja maka semakin tinggi gangguan muskuloskeletal. Hal ini disebabkan oleh penurunan kapasitas fungsional sistem otot dan tulang. ${ }^{9}$ Tidak terdapat hubungan antara umur tenaga kerja dengan keluhan muskuloskeletal dalam penelitian ini dapat dimengerti karena sebagai besar responden berada pada usia di bawah 35 tahun. Keluhan otot skeletal biasanya dialami orang pada usia kerja, 24 - 65 tahun, keluhan pertama dialami pada usia 35 tahun dan tingkat keluhan akan meningkat seiring dengan pertambahan umur. 10

Masa kerja terbukti berhubungan dengan keluhan gangguan muskuloskeletal, berhubungan kuat dengan keluhan otot, dan meningkatkan risiko gangguan muskuloskeletal. ${ }^{11}$ Salah satu faktor yang menyebabkan keluhan muskuloskeletal adalah aktivitas berulang yang dilakukan terus-menerus, sehingga menyebabkan keluhan muskuloskeletal karena otot menerima tekanan akibat beban kerja secara terus-menerus tanpa memperoleh kesempatan relaksasi. ${ }^{1}$ Penelitian sebelumnya menyimpulkan hubungan yang signifikan antara masa kerja dengan keluhan Material Safety Data sheet. ${ }^{12}$

Indeks massa tubuh berhubungan dengan keluhan muskuloskeletal sesuai dengan penelitian sebelumnya yang menyimpulkan hubungan yang signifikan antara indeks massa tubuh dengan keluhan gangguan muskuloskeletal. ${ }^{13}$ Walaupun pengaruhnya kecil, berat badan, tinggi badan, dan massa tubuh dapat menyebabkan keluhan gangguan muskuloskeletal. Wanita yang gemuk, berisiko dua kali lebih besar daripada wanita kurus. Keluhan gangguan sistem muskuloskeletal pada ukuran tubuh lebih disebabkan oleh kondisi keseimbangan struktur rangka di dalam menerima beban, baik beban berat tubuh maupun beban tambahan lainnya. Contoh, tubuh yang tinggi umumnya mempunyai bentuk tulang yang langsing, sehingga secara biomekanik rentan terhadap beban tekan dan rentan terhadap tekukan dan oleh sebab itu mempunyai risiko yang lebih. ${ }^{1}$ Secara teoretis, dapat dijelaskan bahwa keluhan otot skeletal terjadi karena kontraksi otot yang berlebihan akibat pemberian beban kerja yang terlalu berat dengan waktu pembebanan yang panjang. Keluhan otot kemungkinan tidak terjadi apabila kontraksi otot hanya berkisar antara 15 $20 \%$ dari kekuatan otot maksimum. Ukuran tubuh IMT yang memengaruhi keluhan gangguan muskuloskeletal merupakan kombinasi multikausal. ${ }^{14}$

Sikap kerja berhubungan dengan keluhan gangguan 
muskuloskeletal bahwa sikap berdiri merupakan sikap siaga baik fisik dan mental, sehingga aktivitas kerja yang dilakukan lebih cepat, kuat, dan teliti. Pada dasarnya, berdiri lebih melelahkan daripada duduk, energi yang dikeluarkan untuk berdiri lebih banyak $10-15 \%$ dibandingkan duduk. Keluhan gangguan sistem muskuloskeletal yang terkait dengan ukuran tubuh lebih disebabkan oleh kondisi keseimbangan struktur rangka di dalam menerima beban, baik beban berat tubuh maupun beban tambahan lainnya. Contoh, tubuh yang tinggi umumnya mempunyai bentuk tulang yang langsing, sehingga secara biomekanik rentan terhadap beban tekan dan rentan terhadap tekukan. Oleh karena itu berisiko lebih tinggi terhadap keluhan gangguan muskuloskeletal. ${ }^{1}$

Penelitian sebelumnya melaporkan hubungan bermakna antara faktor sikap tubuh/sikap kerja, khususnya posisi berdiri terhadap keluhan gangguan muskuloskeletal. ${ }^{15}$ Berdasarkan temuan ini dapat dijelaskan bahwa salah satu faktor yang berpengaruh terhadap kesehatan tenaga kerja yang berhubungan dengan ergonomi antara lain sikap dan cara kerja, beban kerja yang tidak adekuat, monotonnya pekerjaan, jam kerja yang tidak sesuai, dan kerja yang berulang-ulang. Fungsi ergonomi adalah untuk mendesain tempat kerja, stasiun kerja, peralatan, dan prosedur dari para pekerja agar tidak sampai pada batas menimbulkan rasa lelah, gelisah, dan luka-luka atau kerugian serta secara efisien menuju keberhasilan tujuan perusahaan. ${ }^{14}$

\section{Kesimpulan}

Keluhan muskuloskeletal di PT SSM sebagian besar tergolong sedang dan tinggi. Proporsi keluhan terbanyak terdapat pada bagian jari tangan kiri dan kanan, sementara untuk proporsi yang terkecil terdapat pada jenis keluhan di bagian pantat. Keluhan muskuloskeletal ini dipengaruhi oleh masa kerja, indeks massa tubuh, dan sikap kerja.

\section{Saran}

Pihak manajemen perusahaan disarankan membuat kursi kerja yang ergonomis sehingga tenaga kerja dapat melakukan pekerjaan dalam posisi duduk, agar beban kerja tubuh dapat berkurang. Perlu dibuat rotasi pekerja sesuai dengan ketinggian dimensi tubuh, umur, masa kerja, dan risiko ergonomi pekerjaan. Selain itu, pelatihan kerja atau training tentang risiko ergonomi di tempat kerja dan tata-tata cara bekerja yang sesuai dengan prinsip ergonomi perlu diberikan. Diperlukan pula penelitian lanjutan untuk mengetahui pengaruh paparan suhu rendah (mikroklimat) terhadap gangguan muskuloskeletal.

\section{Daftar Pustaka}

1. Tarwaka. Ergonomi industri. Surakarta: Harapan Press Solo; 2010.

2. Grandjean E. Fitting the task to the man: a textbook of occupational ergonomics. 4th ed. London: Taylor \& Francis; 1993.

3. Bridger RS. Introduction to ergonomic. USA: MC Graw Hill Inc.; 2003.

4. United States Department of Labor. Musculoskeletal disorders and days away from work in 2011. USA: Bureau of Labor Statistic; 2011 [cited 2012 Sept 10]. Available from: http://www.bls.gov/opub/ted/2008/ dec/wk1/art02.htm.

5. Yassierli J. Perancangan alat evaluasi keselamatan kerja berbasiskan PDA. Prosiding Seminar Nasional Ergonomi dan Ikatan Ahli Ilmu Faal Indonesia. 2008 Aug 7-8; Medan. Medan: Ikatan Ahli Ilmu Faal Indonesia; 2008.

6. Vi P. Reducing risk of musculoskeletal disorders through the use of rebar-tying machines. Applied Occupational and Environmental Hygiene. 2003; 18 (9): 649-54.

7. Gellerman SW. Motivasi dan produktivitas. Wandoyo S, editor. Jakarta: PT. Pustaka Binaman Pressindo; 1987.

8. Notoatmodjo. Pendidikan kesehatan dan ilmu perilaku. Jakarta: Rineka Cipta; 2007.

9. Okunribido W. Ageing and work related musculoskeletal disorders. Health and Safety Executive Research Report 2010 [cited 2012 September 10]. RR799. p 1-35 . Available from: www.hse.gov.uk/research/rrpdf/rr799.pdf.

10. Guo HR, Tanaka S, Cameron LL, Seligman PJ, Behrens VJ, Ger J, et al. Back pain among workers in the United States: national estimates and workers at risk. American Journal of Industrial Medicine. 2005; 28 (5)5: 591-602.

11. Cohen AL. Elements of ergonomics programs: A primer based on workplace evaluation of musculoskeletal disorders. Amerika: U.S Department of Health and Human Services NIOSH; 1997.

12. Monteiro MS, Alexandre NS, Rodrigues CM. Work ability and musculoskeletal disorders among workers from a public health institution. International Journal of Occupational Safety and Ergonomics (JOSE). 2009; 15(3): 319-24.

13. Sethi J, Sandhu JS, Imbanathan V. Effect of body mass index on work related musculoskeletal discomfort and occupational stress of computer workers in a developed ergonomic setup. Sports Medicine, Arthroscopy, Rehabilitation, Therapy \& Technology. 2011; 3 (1): 22.

14. Suma'mur PK. Higene perusahaan dan kesehatan kerja. Jakarta: PT. Toko Gunung Agung; 1996.

15. da Costa BR, Vieira ER. Risk factors for work-related musculoskeletal disorders: a systematic review of recent longitudinal studies. American Journal of Industrial Medicine. 2010; 53(3): 285-323. 